\title{
Effect of lactic acid suppositories compared with oral metronidazole and placebo in bacterial vaginosis: a randomised clinical trial
}

\author{
A Joan P Boeke, Janny H Dekker, Jacques Th $M$ van Eijk, Pieter J Kostense, \\ $P$ Dick Bezemer
}

\begin{abstract}
Objective-To compare the effect of lactic acid locally, metronidazole orally and placebo in women with bacterial vaginosis.

Design-Randomised clinical trial.

Setting-30 general practices in the Netherlands.

Patients-125 women consulting the general practitioner for symptomatic bacterial vaginosis.

Main outcome measures-Duration of subjective symptoms, recurrence of symptoms, clinically diagnosed cure, adverse events.

Results-Survival analysis showed a significantly faster disappearance of symptoms in the metronidazole category compared with both lactic acid and placebo $(p=0.0005$ metronidazole $v$ placebo, $p=0.0002$ metronidazole $v$ lactic acid $\mathrm{p}=0.6521$ lactic acid $v$ placebo [The stratified Mantel Cox test]). The median duration until absence of symptoms was 21 days for metronidazole and 80 days for placebo. Disappearance of symptoms did not occur in $50 \%$ of the lactic acid group in 90 days. Recurrence

tobacilli without signs of vaginal inflammation. ${ }^{1}$ It may give abundant and foul smelling discharge and is mostly thought of as a distressing condition with little morbidity. There are, however, indications that higher tract infections, adverse pregnancy outcome and postpartum endometritis are associated with the presence of microorganisms related to bacterial vaginosis. ${ }^{2-7}$

Oral metronidazole has been proven to be effective in the treatment of bacterial vaginosis, ${ }^{89}$ but in up to $40 \%$ of the metronidazole treated women bacterial vaginosis recurs after one to three months. ${ }^{910}$ Because of the possible systemic side effects and the potentially teratogenic properties of metronidazole, other therapeutic agents have been studied. Topical lactic acid is increasingly recommended as a harmless and effective alternative. It is used with the aim to restore the normal environment in the vagina. ${ }^{11-13}$ Former studies were contradictory regarding the therapeutic effect of lactic acid. We conducted a randomised clinical trial to compare the effect of metronidazole orally, lactic acid locally and placebo on the course and recurrence of vaginal symptoms and signs in women with bacterial vaginosis
\end{abstract} rates of symptoms were similar over the treatment categories $(p=0.13$ metronidazole $v$ placebo and $p=0.12$ lactic acid $v$ placebo). After 2 weeks cure rates (cure defined as less than three of four clinical criteria present) were $83 \%, 49 \%$ and $47 \%$ for metronidazole, lactic acid and placebo category respectively. At that time cure rates (cure defined as none of three clinical criteria present) were $10 \%, 0 \%$ and $3 \%$. After four weeks and three months these figures were: $55 \%, 20 \%, 20 \%$ and $64 \%, 28 \%, 28 \%$. No differences in adverse events were found between the three interventions.

Conclusions-Lactic acid suppositories are ineffective, metronidazole capsules are effective on signs and symptoms in bacterial vaginosis. A considerable proportion of the patients recover without active medication.

(Genitourin Med 1993;69:388-392)

Address correspondence to: A J P Boeke, Department of General Practice and Nursing Home Medicine, Nursing Home Medicine, aculty of Medicine, Vrije Universiteit, Amsterdam Van der Boechorststraat 1081 BT Amsterdam
The Netherlands.

The Netherlands. 17 June 1993

\section{Methods}

Study population

The study population comprised 125 women, from 15 to 54 years of age, who visited their general practitioner for vaginal symptoms from November 1987 to May 1990 and in whom a bacterial vaginosis was diagnosed. Vaginal symptoms were defined as itching or irritation in or around the vagina and nonbloody discharge of abnormal amount, colour or odour. The absence of Neisseria gonorrhoeae, Candida albicans, Trichomonas vaginalis, or Chlamydia trachomatis was required. The women should not be pregnant or breast feeding, have no sign of a pelvic inflammatory disease, should have no sign of cervical cancer and should not have taken antimicrobial or vaginal medication in the preceding two weeks. They were seen by 30 general practitioners (23 in Amsterdam, three in Utrecht and four in an urbanized area in the east of Holland). All women fulfilling the eligibility criteria were enroled in the study after giving informed consent.

\section{Introduction}

Bacterial vaginosis is a disturbance of the vaginal flora with overgrowth of anaerobic bacteria. Gardnerella vaginalis and lack of lac-
Bacterial vaginosis

Bacterial vaginosis was defined as the presence of any three of four criteria: homoge- 
neous discharge, $\mathrm{pH}$ greater than $4 \cdot 5$, clue cells in the wet mount and a positive amine test. $^{14}$

\section{Clinical evaluation}

The general practitioner performed a speculum examination paying specific attention to the amount, colour and consistency of the discharge. Swabs were taken from the endocervix and posterior fornix for culture and for the ELISA test for Chlamydia trachomatis. The $\mathrm{pH}$ of the discharge was measured using $\mathrm{pH}$-indicator paper (Specia) and the aminetest was performed. A saline wet mount was examined for trichomonads, clue cells and leucocytes and a potassium hydroxidemixed wet mount for the presence of pseudohyphae of yeasts. Symptoms, signs, results of laboratory tests and demographic information were registered on standardised forms. All general practitioners were trained before and during the study in judging the discharge, taking material for cultures and the ELISA test, performing the laboratory tests for the diagnosis of bacterial vaginosis, and working according to the study protocol to optimise the interdoctor concurrency. ${ }^{15}$

All patients completed a pre-coded questionnaire addressing medical history, duration and severity of symptoms, reasons for encounter, sexual behaviour, contraceptive methods and vaginal hygiene habits.

\section{Microbiological methods}

The swabs were transported in Amies medium for culture of Neisseria gonorrhoeae, Trichomonas vaginalis, Candida albicans and Gardnerella vaginalis to the laboratory and processed within six hours after collection of the specimens. All isolates were identified according to standard microbiological methods. ${ }^{16}$ The cervical specimen was tested with ELISA for Chlamydia trachomatis within five days, according to the instructions of the manufacturer (Chlamydiazyme, Abbott).

\section{Treatment and randomisation}

Each woman was allocated at random to one of three categories of treatment: 1) metronidazole capsules orally, $500 \mathrm{mg}$ twice daily + one placebo vaginal suppository every night during one week, 2) placebo capsules orally twice daily + one lactic acid vaginal suppository (100 mg lactic acid pure material in polyethylene glycol $1540 \quad 2 \cdot 4$ gr with a buffered $\mathrm{pH}$ of 3.3) every night for one week, and 3) placebo capsules twice daily $+a$ placebo vaginal suppository at night during one week. Randomisation was balanced in time in such a way that each treatment was allocated twice in a group of six subsequent women.

\section{Follow-up}

Women were seen at 2 weeks, 4 weeks and 3 months after the start of the treatment. During these visits a speculum examination and laboratory tests were performed. Each time a questionnaire containing questions concerning the level of symptoms and even- tual date of experienced recovery or improvement was filled out by the patients.

\section{Outcome}

The first subjective outcome measure was the number of days between the start of medication and the day on which occasional recovery occurred according to the patients' experience. Recurrence given recovery was the second subjective outcome measure.

Cure as an objective outcome measure was defined at two levels of strictness: 1. Marginal cure definition: if less than three of the four criteria were present, and 2. Strict cure definition: if none of the three following criteria was present: a $\mathrm{pH}$ greater than $4 \cdot 5$, a positive amine test and the presence of clue cells. These criteria were proven to have the strongest association with the syndrome diagnosis. ${ }^{217} 18$

\section{Adverse events}

Adverse symptoms were registered by patients, and the frequency of occurrence of Candida albicans infections as a potential side effect of metronidazole was determined by microscopic inspection and by culture.

\section{Required sample size}

A difference of $30 \%$ in the proportion of objectively cured patients between both treatment categories and the placebo category at the first follow-up measurement was considered as an important difference not to be missed in this trial. It was known from earlier studies that the cure rate in the metronidazole category would be approximately $80 \%$. Using a two-tailed test with a significance level of $5 \%$ and with a power of $90 \%$ we would need to enrol 48 patients per treatment category. ${ }^{19}$

\section{Statistical analysis}

Differences in duration of symptoms by treatment were analysed with the Cox proportional hazards model to control for potential confounding and to optimally estimate hazard ratios, using BMDP (version PC90). In the event of limited confounding Kaplan-Meier functions and the log-rank test were used. ${ }^{20}$ Recurrence rates were compared by means of the $\chi^{2}$-test.

The proportions cured from bacterial vaginosis were compared on the three follow-up points of time. Confidence intervals of differences of these proportions were computed according to Miettinen. ${ }^{21}$ Further analyses of these outcome measures were performed by means of multiple logistic regression. All potentially confounding variables were considered for model fitting. Modification for duration of symptoms (subjective) and for proportions cured (objective) were studied by introduction of product terms in the logistic functions.

\section{Results}

\section{Study population}

193 patients were eligible for the study, according to the criteria measured by the general practitioner. Twenty-five patients refused 
Table 1 Distribution of baseline characteristics in the different treatment categories. (missing values not presented).

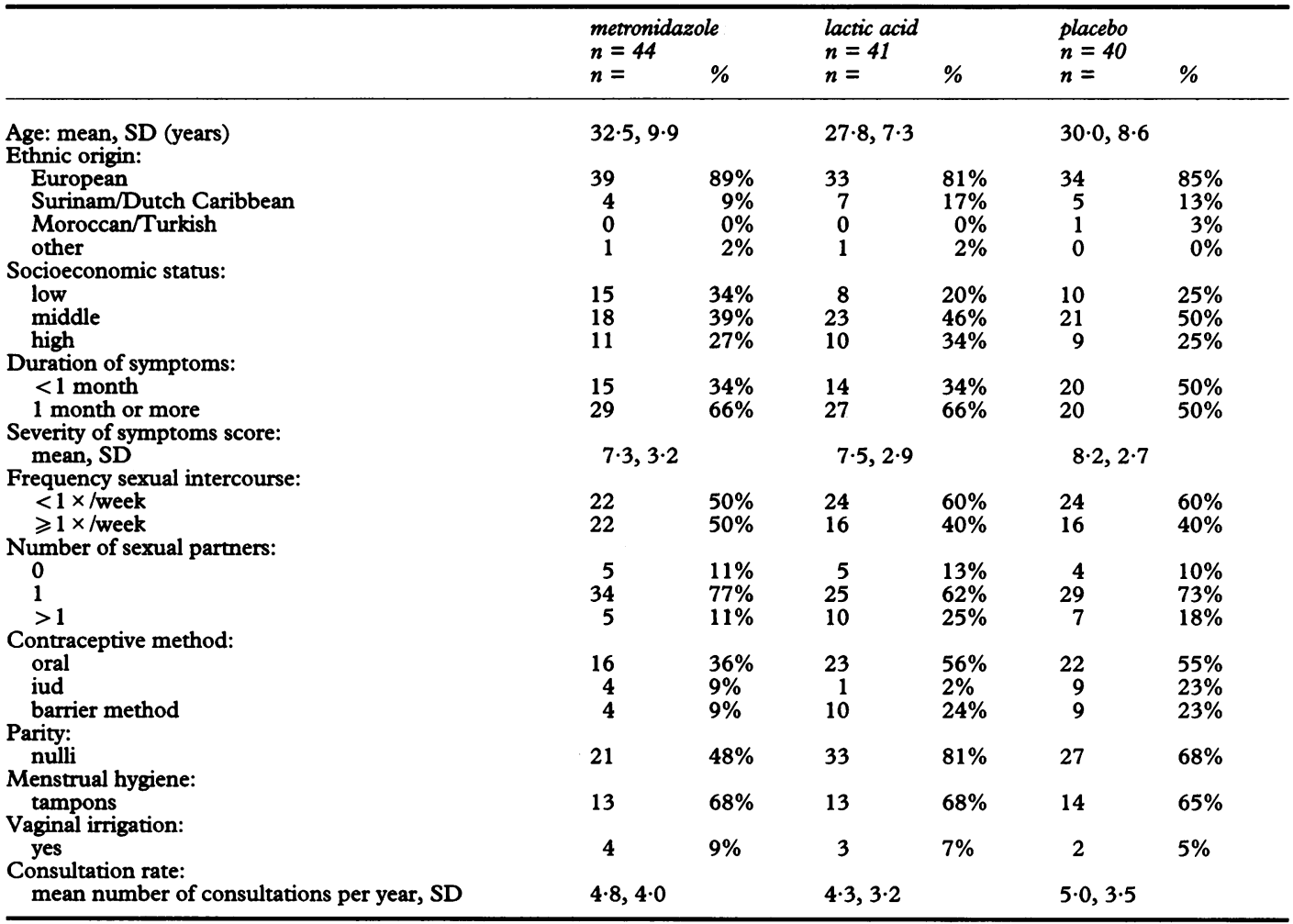

cooperation. 168 women were enroled in the study and received medication in a randomised way. After the enrolment and randomisation, 43 women appeared to have positive cultures for yeasts, trichomonas, or gonorrhoea or a positive ELISA test for Chlamydia trachomatis, leaving 125 for the analysis.

\section{Baseline characteristics}

Table 1 shows the distribution of baseline characteristics over the three treatment categories. The following potentially confounding variables were shown to be unequally distributed: duration of symptoms, socio-economic status, frequency of sexual intercourse and parity. All variables presented in table 1 were used for fitting the proportional hazards model and the logistic regression model.

Culture of Gardnerella vaginalis was positive in 97 of the 125 eligible women (78\%).

Follow-up and drop-out

Twenty-three patients dropped out during follow-up. They did not differ from the others concerning duration and severity of symptoms at baseline. The drop outs were younger than the women who completed participation in the study. The distribution of the reasons of cessation was virtually the same over the treatment categories.

\section{Compliance}

At the first follow-up all participants were asked to register the number of suppositories and capsules they had actually taken. The compliance according to the patients' reporting was comparable between the three intervention categories.

\section{Subjective outcome}

1) The course of vaginal symptoms: time until recovery.

The crude survival functions of the duration of symptoms (Kaplan-Meier) for the three treatment categories are shown in the fig. The median duration until recovery was 21 days for metronidazole and 80 days for placebo. $50 \%$ of the lactic acid category did not recover after 90 days.

2) Recurrence of vaginal symptoms.

Sixty-five of the 125 women experienced recovery after a certain number of days. In 24 of 60 recovered patients available for analysis the recurrence rates were $13 / 29$ for metronidazole, $7 / 14$ for lactic acid and $4 / 17$ for placebo $(p=0.13$ metronidazole vs placebo and $p=0.12$ lactic acid vs placebo)

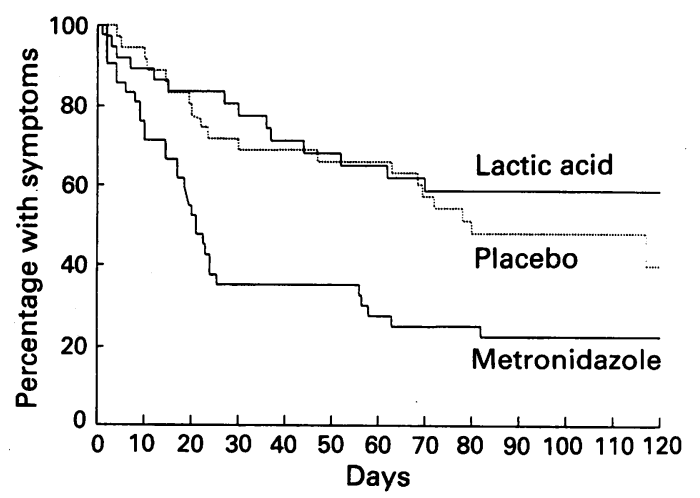

The survival function of duration of symptoms by treatment category estimated by the product-limit method (Kaplan-Meier). The stratified Mantel Cox test: $p=0.0005$ contrast metronidazole and placebo, $p=0.6521$ contrast lactic acid and placebo, $p=0.0002$ contrast metronidazole and lactic acid. 
Table 2 Patients cured by treatment category. * 95\% confidence intervals ( $c i)$ of differences between metronidazole ( $m$ ) and placebo ( $p$ ) and between lactic acid (l) and placebo ( $p)$.

\begin{tabular}{llllll}
\hline & metronidazole & lactic acid & placebo & $\begin{array}{l}95 \% \text { ci } \\
\text { difference } m-p\end{array}$ & $\begin{array}{l}95 \% \text { ci } \\
\text { difference }-p\end{array}$ \\
\hline 2 Weeks proportion cured & $35 / 42(83 \%)$ & $18 / 37(49 \%)$ & $16 / 34(47 \%)$ & {$[15$ to 55$]$} & {$[-21$ to 24$]$} \\
4 Weeks proportion cured & $27 / 38(71 \%)$ & $11 / 33(33 \%)$ & $12 / 35(34 \%)$ & {$[14$ to 56$]$} & {$[-23$ to 22] } \\
3 Months proportion cured & $29 / 37(78 \%)$ & $12 / 32(38 \%)$ & $11 / 32(34 \%)$ & {$[12$ to 63] } & {$[-20$ to 26] } \\
\hline
\end{tabular}

^Cure defined as: less than 3 of 4 criteria for bacterial vaginosis (homogeneous discharge, $\mathrm{pH}>4 \cdot 5$, clue cells, amine-test positive).

Table 3 Patients cured by treatment category. ${ }^{*} 95 \%$ confidence intervals (ci) of differences between metronidazole (m) and placebo ( $p)$ and between lactic acid (i) and placebo ( $p)$.

\begin{tabular}{llllll}
\hline & metronidazole & lactic acid & placebo & $\begin{array}{l}95 \% \text { ci } \\
\text { difference } m-p\end{array}$ & $\begin{array}{l}95 \% \text { ci } \\
\text { difference } l-p\end{array}$ \\
\hline 2 Weeks proportion cured & $4 / 42(10 \%)$ & $0 / 37(0 \%)$ & $1 / 34(3 \%)$ & {$[-7$ to 20$]$} & {$[-15$ to 7$]$} \\
4 Weeks proportion cured & $21 / 38(55 \%)$ & $7 / 35(20 \%)$ & $7 / 35(20 \%)$ & {$[13$ to 54$]$} & {$[-19$ to 19$]$} \\
3 Months proportion cured & $23 / 36(64 \%)$ & $9 / 32(28 \%)$ & $9 / 32(28 \%)$ & {$[12$ to 56$]$} & {$[-22$ to 22$]$} \\
\hline
\end{tabular}

*Cure defined as: none of the three following criteria present: $\mathrm{pH}>4 \cdot 5$, amine-test, clue cells.

\section{Objective outcome}

1) Proportion of patients cured (marginal cure)

Table 2 shows the proportion of women cured per category on each follow-up measurement. On all follow-up points of time, the $95 \%$ confidence intervals of rate differences between metronidazole and placebo did not include 0 , which implies that these differences were significantly different from zero. No difference could be found between lactic acid and placebo.

In multiple regression analysis none of the potentially confounding variables could be identified as an actual confounder, nor could a significant effect modification be found.

2) Proportion of patients cured (strict cure) After two weeks, the proportion cured in the three categories was $10 \%$ or less and no significant difference was shown between the treatment groups (table 3 ). Only after four weeks, could a significant difference be found between metronidazole and placebo. This difference also occurred after 3 months.

\section{Adverse events}

Table 4 shows the occurrence of symptoms attributed by the participants themselves to the treatment they had taken. None of the symptoms reflected a clear difference in frequency of occurrence among the three groups. In the lactic acid category no vaginal Candida albicans infection was detected versus five in the metronidazole and three in the placebo group.

Table 4 Adverse signs and symptoms

\begin{tabular}{llll}
\hline & metronidazole & lactic acid & placebo \\
\hline available & 40 & 33 & 35 \\
SUBJECTIVE & $\mathrm{n}(\%)$ & $\mathrm{n}(\%)$ & $\mathrm{n}(\%)$ \\
gastrointestinal & $3(7)$ & $4(12)$ & $4(11)$ \\
symptoms & & & \\
vaginal symptoms & $3(8)$ & $3(9)$ & $1(3)$ \\
headache, vertigo & 0 & $1(3)$ & $1(3)$ \\
bad taste & $1(3)$ & 0 & 0 \\
other & $1(3)$ & 0 & $2(6)$ \\
none & $32(80)$ & $25(76)$ & $28(80)$ \\
OBJECTIVE & & & $3(9)$ \\
Candida albicans & $5(13)$ & 0 & 3 \\
\hline
\end{tabular}

*contrast metronidazole vs placebo: $p=0.86$ (Fisher exact test); contrast metronidazole vs lactic acid: $p=0 \cdot 10$ (Fisher exact test).

\section{Discussion}

The hypothesised effect of lactic acid on bacterial vaginosis could not be proved in any of the outcome measurements during three months follow-up. The data agree with the results of the study done by Fredricsson et al, but contradict the studies by Andersch et al and by Holst et al. ${ }^{11-13}$ Both studies that claim a success of treatment by acidification were not double blinded. This could have influenced the outcome considerably.

We opted for application of suppositories as the vehiculum of the lactic acid. In the studies mentioned above concerning local treatment with lactic acid, a lactate gel was used with a buffered $\mathrm{pH}$ of $3 \cdot 8$. Further studies should be carried out to find out if and how the potential effect of acidifying agents depends on the amount of acid applied, the concentration of it and the mode of application.

Metronidazole appeared to be an efficacious drug although it was not immediately effective, according to the patients' experience: only $50 \%$ considered themselves recovered after 21 days. This protracted recovery was also displayed in the strictly defined cure rates according to Eschenbach: $10 \%, 55 \%$ and $64 \%$ after 2 weeks, 4 weeks and 3 months. Unexpectedly, recurrence rates were lower compared with lactic acid. The number and character of the adverse events were similar in the three treatment categories.

Remarkably almost half of the placebo treated group was objectively cured (marginal cure definition) after 2 weeks, while the proportion of cured patients decreased to $34 \%$ both after 4 weeks and 3 months. According to the strict definition of cure the rates were $1 \%, 20 \%$ and $28 \%$. This might be explained by the content of the placebo suppositories. They existed merely of polyethylene glycol 1540 , which is inert and pH-neutral. Yet a slight antibacterial effect of a suppository can not be excluded caused by a short hyperosmotic effect on the vaginal environment after application. But this is expected not to be clinically relevant. On the other hand the increase of discharge and dilution by introduction of the suppositories could have possibly relieved symptoms. 
We conclude that a structural improvement of the ecological disturbance is implemented by metronidazole for a majority of the women with symptomatic bacterial vaginosis, but obviously not for all and that not all women need metronidazole for a recovery from bacterial vaginosis. Lactic acid appeared to have no favourable effect on the course of bacterial vaginosis.

Consequently the general practitioner should be guided in his treatment of patients with bacterial vaginosis by their distress and the severity of symptoms. He might propose an expectative policy, particularly if the duration of symptoms is shorter than 1 month, since the probability of spontaneous cure is considerable. ${ }^{22}$ If cure is required in the short term, metronidazole is the medication to be chosen, if the women is not pregnant. More research has to be done to evaluate alternative treatment of bacterial vaginosis in pregnancy.

1 Hillier S, Holmes KK. Bacterial vaginosis In: Holmes KK Mårdh PA, Sparling PF, Wiesner PJ, eds. Sexually Transmitted Diseases, 2nd ed, New York: McGraw-Hill Book Company, 1990.

2 Eschenbach DA, Hillier S, Critchlow C, Stevens C, DeRouen T, Holmes KK. Diagnosis and clinical manifestations of bacterial vaginosis. Am $\mathcal{f}$ Obstet Gynecol 1988;158:19-28.

3 Gravett MG, Nelson HP, De Rouen T, Critchlow C, Eschenbach DA, Holmes KK. Independent associations of bacterial vaginosis and Chlamydia trachomatis infecof bacterial vaginosis and Chlamydia trachomatis infec-
tion with adverse pregnancy outcome. $¥ A M A 1986 ; 256$ : tion with $1899-903$.

4 McGregor JA, French J, Richter R, et al. Antenata microbiologic and maternal risk factors associated with prematurity. Am $\mathcal{Y}$ Obstet Gynecol 1990;163:1465-73.

5 Martius J, Krohn MA, Hillier S, et al. Relations of vagina lactobacillus species, cervical Chlamydia trachomatis, and bacterial vaginosis in preterm birth. Obstet Gynecol 1988;71:89-95.
6 Newton ER, Prihoda TJ, Gibbs RS. A clinical and microbiologic analysis of risk factors for puerperal endometritis. Obstet Gynecol 1990;75:402-6.

7 Watts DH, Eschenbach DA, Kenny GE. Early postpartum endometritis: the role of bacteria, genital mycoplasmas, and Chlamydia trachomatis. Obstet Gynecol mas, and $1989 ; 73: 52-60$

8 Balsdon MJ, Pead L, Taylor GE, Maskell $R$. Corynebacterium vaginale and vaginitis: a controlled trial of treatment. Lancet 1980;ii:501-3.

9 Blackwell AL, Phillips I, Fox AR, Barlow D. Anaerobic vaginosis (non-specific vaginitis): clinical, microbiologi$\mathrm{cal}$ and therapeutic findings. Lancet 1983;ii:1379-82.

10 Wathne B, Hovelius B, Holst E. Cefadroxil as an alternative in the treatment of bacterial vaginosis. Scand $\mathcal{F}$ Infect Dis 1989;21:585-6.

11 Andersch B, Forssman L, Lincoln K, Torstensson P. Treatment of bacterial vaginosis with an acid cream: a comparison between the effect of lactate-gel and comparison between the effect of lactate-gel

12 Fredricsson B, Englund K, Weintraub L, Ölund A, Nord C. Bacterial vaginosis is not a simple ecological disorder. Gynecol Obstet Invest 1989;28:156-60.

13 Holst E, Brandberg A. Treatment of bacterial vaginosis in pregnancy with a lactate gel. Scand $\mathcal{f}$ Infect Dis 1990;22:625-6.

14 Amsel R, Totten PA, Spiegel CA, Chen KC, Eschenbach $\mathrm{D}$, Holmes KK. Nonspecific vaginitis. Diagnostic criteria and microbial and epidemiologic associations. $A m \mathcal{F}$ Med 1983;74:14-22.

15 Boeke AJP, Faas A. Interdoctor concurrence in the diagnosis of vaginitis. IInter-dokterbetrouwbaarheid bij de diagnostiek van vaginitis]. Huisarts Wet 1985;28:395-7.

16 Lennette EH, Balows A, Hausler WJ, Shadomy HJ, eds. Manual of Clinical Microbiology. 4th ed. Washington DC: American Society for Microbiology, 1985

17 Thomason $\pi$, Gelbart SM, Anderson RJ, Walt AK, Osypovski PJ, Broekhuizen FF. Statistical evaluation of diagnostic criteria for bacterial vaginosis. Am $₹$ Obstet Gynecol 1990;162:155-60.

18 Krohn MA, Hillier S, Eschenbach DA. Comparison of methods for diagnosing bacterial vaginosis among pregnant women. f Clin Microbiol 1989;27:1266-71.

19 Fleiss JL. Statistical Methods for Rates and Proportions. New York: Wiley and Sons, 1981

20 Armitage P, Berry G. Statistical Methods in Medical Research, 2nd ed. Oxford: Blackwell Scientific Publications, 1987.

21 Miettinen OS. Theoretical epidemiology. Principles of Occurrence Research in Medicine. New York: Wiley and Sons, 1985.

22 Bump RC, Zuspan FP, Buesching WJ, Ayers LW, Stephens TJ. The prevalence, six month persistence, and predictive values of laboratory indicators of bacterial vaginosis (non specific vaginitis) in asymptomatic women. Am $₹$ Obstet Gynecol 1984;150:917-24. 